\title{
Primary Care Physician Insights Into a Typology of the Complex Patient in Primary Care
}

Danielle F. Loeb, $M D^{1}$

Ingrid A. Binswanger, $M D, M P H^{1,2}$

Carey Candrian, $\mathrm{PbD}^{1}$

Elizabeth A. Bayliss, MD, MSPH ${ }^{2,3}$

'University of Colorado, Division of General Internal Medicine, Aurora, Colorado

${ }^{2}$ Institute for Health Research, Kaiser Permanente Colorado, Denver, Colorado

${ }^{3}$ University of Colorado, Department of Family Medicine, Aurora, Colorado

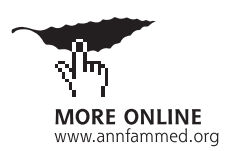

Conflicts of interest: authors report none.

\section{CORRESPONDING AUTHOR}

Danielle F. Loeb, MD

Academic Office 1, Mailstop B180

University of Colorado School of Medicine 12631 E 17th Ave

Aurora, CO 80045

Danielle.loeb@ucdenver.edu

\begin{abstract}
PURPOSE Primary care physicians play unique roles caring for complex patients, often acting as the hub for their care and coordinating care among specialists. To inform the clinical application of new models of care for complex patients, we sought to understand how these physicians conceptualize patient complexity and to develop a corresponding typology.
\end{abstract}

METHODS We conducted qualitative in-depth interviews with internal medicine primary care physicians from 5 clinics associated with a university hospital and a community health hospital. We used systematic nonprobabilistic sampling to achieve an even distribution of sex, years in practice, and type of practice. The interviews were analyzed using a team-based participatory general inductive approach.

RESULTS The 15 physicians in this study endorsed a multidimensional concept of patient complexity. The physicians perceived patients to be complex if they had an exacerbating factor-a medical illness, mental illness, socioeconomic challenge, or behavior or trait (or some combination thereof)-that complicated care for chronic medical illnesses.

CONCLUSION This perspective of primary care physicians caring for complex patients can help refine models of complexity to design interventions or models of care that improve outcomes for these patients.

Ann Fam Med 2015;13:451-455. doi: 10.1370/afm.1840.

\section{INTRODUCTION}

$\mathrm{P}$ rimary care physicians (PCPs) play unique roles caring for complex patients, often acting as the hub for their care and coordinating care among specialists. Algorithms that focus on numbers of conditions, medications, or both, however, may not align with clinicians' definitions of complexity. ${ }^{1,2}$ Early definitions of patient complexity focused on those factors. ${ }^{2,3}$ Newer models of complexity have been developed that incorporate mental health, social influences, and economic factors that substantially affect chronic disease outcomes. ${ }^{4-14}$ For example, building on the work of Stiefel et $\mathrm{al}^{10}$ with the INTERMED instrument, Peek et $\mathrm{al}^{4}$ developed the Minnesota Complexity Assessment Method, which assesses 5 domains: illness (both medical and mental illness), readiness to engage, social, health system, and resources for care. It is unclear, however, whether PCPs' perceptions of complexity are aligned with these newer models.

If endorsed by PCPs, newer models of complexity could potentially contribute to improving algorithms for risk adjustment for primary care patient panels, controlling for complexity in secondary database analysis, and designing interventions for complex patients. To inform the clinical application of new models of care for complex patients, we sought to understand how PCPs conceptualize patient complexity and to develop a corresponding typology.

\section{METHODS}

We used a qualitative study design to conduct in-depth, open-ended interviews with PCPs. Using systematic nonprobabilistic sampling to achieve a 
balanced distribution of sex, years in practice, and type of practice, we recruited physicians from 2 university clinics and 3 community health clinics. ${ }^{15}$ We limited our study to internal medicine physicians to increase consistency in their training background. After 3 initial pilot interviews, we sent invitations to participate by e-mail to all physicians in the practices, including 34 and 28 physicians from the university and community health clinics, respectively. We reached saturation after interviewing 10 participants, so we completed the interview process after 15 interviews with 8 university clinic and 7 community health clinics participants.

We conducted one-on-one, semistructured interviews focused on PCP experiences with complex patients in general, with additional focus on specific patient-level factors that contribute to patient complexity. To facilitate the discussion, each of the PCPs brought deidentified notes from 3 patients they considered complex. During the interviews, interviewers explored how PCPs identified patients as complex. Interview questions also included broad impressions of complex patients and specific factors that contributed to patient complexity (Supplemental Appendix A, available at http://www.annfammed.org/ content/13/5/451/suppl/DC1). Members of the team included health services researchers, including 2 general internists (D.F.L. and I.A.B.) and 1 family medicine physician (E.A.B.) and an exper in health communica-

\section{Table 1. Physician Characteristics ( $\mathrm{N}=15)$}

\begin{tabular}{lc}
\hline Characteristic & Value \\
\hline Age, mean (range) [median], y & $38(29-52)$ [38] \\
Female, No. (\%) & $9(60)$ \\
Race/ethnicity, No. (\%) & $12(80)$ \\
White non-Hispanic & $2(13)$ \\
Asian & $1(7)$ \\
White Hispanic & $7(47)$ \\
Clinic type: community health (vs uni- \\
$\quad$ versity), No. (\%) \\
$\begin{array}{l}\text { Time since residency completion, mean } \\
\text { (range) [median], y }\end{array}$ \\
$\begin{array}{l}\text { Time in primary care practice, mean } \\
\text { (range) [median], y }\end{array}$ \\
\hline
\end{tabular}

tion (C.C.). The principal investigator (D.F.L.) and another team member (C.C.) conducted the interviews.

Interviews were audio-recorded and transcribed transcript files were coded using qualitative data analysis software (ATLAS.ti, Scientific Software Development $\mathrm{GmbH}$ ). The interviews were analyzed using a team-based participatory general inductive approach. D.F.L. performed initial coding and developed an initial coding scheme.$^{16}$ Codes were broadly categorized into discrete factors contributing to complexity. Using the initial coding scheme, 2 other team members (I.A.B. and E.A.B) then independently coded 2 interviews, suggested additional codes, and worked with D.F.L. to resolve coding differences. The team (including C.C.) agreed on the final codebook to guide the rest of the coding, conducted by D.F.L. The team also met as a group to discuss emerging themes. The Colorado Multiple Institutional Review Board approved this study.

\section{RESULTS}

Table 1 shows characteristics of the 15 participating physicians. They were 38 years old, on average, and predominantly female and white. They had been in primary care practice for a mean of 7 years.

Participants described a typology of 4 overarching categories contributing to patient complexity: medical complexity, mental health disorders, socioeconomic factors, and individual patient behaviors or traits (Figure 1).

Within the category of medical complexity, PCPs emphasized patients with a discordant condition-a condition whose management differs from or competes with management of a comorbid condition, such as a chronic infection in a patient with an autoimmune disease. A university clinic PCP gave the following example of a medically complex patient:

So he has cirrhosis in his transplanted liver due to hepatitis $\mathrm{C}$ infection. And then he has a hernia in his abdomen that he can't have operated on because he is a poor surgical candidate. Because of that hernia, he has chronic abdominal wounds...that don't heal well despite ongoing wound care efforts. So...those are about 4 different things that really complicate each other in his case.

\section{Figure 1. Typology of complex patients.}

\begin{tabular}{|c|c|c|c|}
\hline $\begin{array}{l}\text { Medical Complexity } \\
\text { Discordant conditions } \\
\text { Chronic pain } \\
\text { Medication intolerance } \\
\text { Unexplained symptoms } \\
\text { Cognitive issues }\end{array}$ & $\begin{array}{l}\text { Socioeconomic Factors } \\
\text { Exacerbating Medical } \\
\text { Condition } \\
\text { Inability to afford medica- } \\
\text { tions, transportation } \\
\text { Family stressors } \\
\text { Poor health care literacy }\end{array}$ & $\begin{array}{c}\text { Mental Illness } \\
\text { Exacerbating Medical } \\
\text { Condition } \\
\text { Depression leading to poor } \\
\text { medication adherence } \\
\text { Addiction } \\
\text { Anxiety confusing clinical } \\
\text { picture }\end{array}$ & $\begin{array}{c}\text { Patient Behaviors } \\
\text { and Traits } \\
\text { Demanding (tests, } \\
\text { medication) } \\
\text { Argumentative (with staff } \\
\text { or physicians) } \\
\text { Anxious (regarding } \\
\text { symptoms) }\end{array}$ \\
\hline
\end{tabular}


PCPs described multiple ways in which mental illness complicated the care of chronic medical illness, including interfering with self-care and adherence with therapies. One community health clinic PCP described the interaction between mental and medical illnesses:

I think the more difficult thing... the severe depression, the not-terribly-responsive-to-treatment depression, or the depression that is sort of colored by their frustration by their medical comorbidities. That I think really affects the management of their medical problems because of the hopelessness, and that affects adherence and other things.

Similarly, participants portrayed multiple psychosocial situations in which financial limitations interfered with patients' ability to fill prescriptions, follow through with medical appointments, or care for themselves.

Community health clinic participants strongly emphasized the contribution of psychosocial challenges, in particular financial barriers to care. For example:

I think homelessness is a big one also.... For instance, I just saw a guy who... who goes between all of his daughters' houses... And I can't ever figure out what phone number to get him at. He always comes in with a different daughter who was supposedly giving him his medicines... his medicines get misplaced between visits. Between traveling between daughters.

Participants also described social situations patients encounter, such as partners who abuse them or children in jail, that led to high levels of stress and interfered with their medical care.

Finally, PCPs differentiated complex patients from "difficult patients." They defined the latter as those who have difficult personalities but not necessarily complex medical conditions: "In my mind, when most people talk about a difficult patient, they talk about the ones that frustrate them. And sometimes that is somebody who is complex. Often that is just somebody who is hard to get along with..." PCPs, however, did identify patients who had chronic illness and also had challenging behaviors, such as regularly arguing with office staff, as complex. They explained that these patients strained the clinic's systems for the management of chronic illness. A university clinic PCP described a patient with serious medical illness and challenging behaviors:

So literally every time [she has contact with] the hospital, somebody from somewhere sends me a note saying we just talked to this patient and they were totally inappropriate. On top of that, she has a condition that needs to be monitored periodically, and if it is not monitored appropriately could be fatal, and I don't feel like she really fully understands that. So she has...this impressive ability to alienate all these people who can potentially help her and also to reject the system that is in place to make sure...that the bad outcomes don't happen.

A theme of lack of control emerged as an explanation for why particular factors led to PCPs categorizing patients as complex. This theme was particularly strong when participants described social factors. One community health clinic physician pointed to a lack of ability to control social factors by contrasting the vast resources available to effect change for medical factors compared with social factors.

If they have uncontrolled CHF [congestive heart failure], I have the knowledge that I can try to help them and change their medications, or I have a bazillion things I can think of for that patient to do. I also have a good network of specialists I can refer them to.... I have a hospital to put them in.... For their social network, I have little. I cannot make a patient not go back to her husband who beats her. I cannot have someone-an elderly woman who lives with her drunk son-stop living with him and have her go to an assisted living or something if she doesn't want to.

PCPs also described patients with symptoms that they could not control as complex. One community health clinic participant stated, "I think [a complex patient] is somebody that... I have difficulty controlling their symptoms for whatever reason... because of psychosocial factors, economic factors, transportation difficulties."

In terms of their predominant view of complexity, PCPs in this study reported that patients whom they considered complex had exacerbating factors beyond the presence of multiple medical conditions. One description of complexity by a university clinic participant captured this general theme: "I think for me, a complex patient is a patient who makes me think [about the patient when I am] outside of the exam room...."

\section{DISCUSSION}

PCPs in this study endorsed a multidimensional concept of patient complexity incorporating medical illnesses, mental illnesses, socioeconomic challenges, and/or behaviors or traits that complicated care for chronic medical illnesses.

Although PCPs identified specific factors that led to complexity in their patients, most also broadly defined complex patients as those who did not easily fit into guidelines or algorithms - exemplified by the PCP who defined complex patients as those who "make me think outside of the room." This overarching description of complex patients provided by most PCPs in this study correspond to the concept of Peek et $\mathrm{al}^{4}$ of "patient complexity" as "the person-specific factors that interfere 
with the delivery of usual care and decision-making for whatever conditions the patient has." In contrast to these definitions based on the PCP perspective, Shippee et $\mathrm{al}^{14}$ developed a definition of complexity in their cumulative complexity model focused on patients' functional status. This model concentrates on the balance of the "workload" related to patients' medical care and other self-care and their "capacity" to perform the activities necessary to care for themselves. The difference in these definitions reflects the perspective of PCPs vs patients. This difference also illustrates the importance of considering the users and purpose of the complexity assessment when choosing a model of complexity.

Our findings add qualitative detail that supports and expands on the previous cohort study by Grant et al ${ }^{1}$ in which PCPs identified complex patients as having medical, social, and behavioral factors beyond comorbidity. The categories of complex patients identified by PCPs in our study integrate well into 2 recently proposed conceptual models: (1) the Agency for Healthcare Research and Quality's Multiple Chronic Conditions Research Network (MCCRN) model ${ }^{12}$ and (2) a model based on comorbidity interrelatedness developed by Zulman et al. ${ }^{13}$ The MCCRN model is a broad or "ecological" conceptual model based on a review of the literature. This model defines complexity as the gap between patient needs and the services available to them, and incorporates economic, social, and physical factors as "contextual factors" influencing patient needs, the services available, or both. The model of Zulman et al emphasizes the characteristics of medical conditions, such as symptom intensity and comorbidity interrelatedness. In our study, mental health conditions complicating medical illness and discordant conditions parallel this concept of comorbidity interrelatedness. In addition, the socioeconomic factors and patient behaviors and traits parallel the behavioral/environmental characteristics category of Zulman et al. Participants in our study emphasized the mental health and behavioral factors more strongly than Zulman does in her model. Alternatively, the ecological MCCRN model fully explores behavioral and environmental factors while placing minimal emphasis on the medical aspect of complexity. Our findings would support augmenting the MCCRN model with the more detailed exploration of clinical complexity offered in the model of Zulman et al.

The primary limitation of our study is that all of the physicians were affiliated with a single university system. The study did include, however, academic clinics as well as community health clinics, both of which serve a high proportion of complex patients.

This study offers the perspectives of PCPs caring for complex patients to guide the refinement of models of complexity that can be used to design interven- tions or models of care to improve outcomes for these patients. Comprehensive models of complexity that incorporate these new perspectives can inform the organization of care for complex patients through team-based interventions addressing medical health, mental health, and socioeconomic aspects of care.

To read or post commentaries in response to this article, see it online at http://www.annfammed.org/content/13/5/451.

Key words: chronic care; comorbidity/multimorbidity; primary care issues; qualitative methods; key informant/depth interviewing; social factors in health and health care; mental health; practice-based research

Submitted March 19, 2015; submitted, revised, June 19, 2015; accepted July 6, 2015.

Funding support: This study was funded by the University of Colorado Division of General Internal Medicine Small Grants program. Danielle Loeb, MD received salary support through the University of Colorado Primary Care Research Fellowship funded by Health Resources and Services Administration and National Institute of Mental Health Mentored Patient-Oriented Research Award 1K23MH100162-01A1.

Disclaimer: The content is solely the responsibility of the authors and does not necessarily represent the official views of any of the funders.

Previous presentation: We presented an earlier version of the manuscript as a poster at the Annual Society of General Internal Medicine Meeting, May 9-12, 2012; Orlando, Florida.

Acknowledgments: We acknowledge Carolyn Nowels for her assistance with qualitative analysis.

Supplementary materials: Available at http://www.AnnFamMed. org/content/13/5/451/suppl/DC1/

\section{References}

1. Grant RW, Ashburner JM, Hong CS, Chang Y, Barry MJ, Atlas SJ. Defining patient complexity from the primary care physician's perspective: a cohort study. [published correction appears in Ann Intern Med. 2012;157(2):152]. Ann Intern Med. 2011;155(12):797-804.

2. de Groot V, Beckerman H, Lankhorst GJ, Bouter LM. How to measure comorbidity. A critical review of available methods. J Clin Epidemiol. 2003;56(3):221-229.

3. Huntley AL, Johnson R, Purdy S, Valderas JM, Salisbury C. Measures of multimorbidity and morbidity burden for use in primary care and community settings: a systematic review and guide. Ann Fam Med. 2012;10(2):134-141.

4. Peek CJ, Baird MA, Coleman E. Primary care for patient complexity, not only disease. Fam Syst Health. 2009;27(4):287-302.

5. Marmot MG, Wilkinson RG. Social Determinants of Health. 2nd ed. New York, NY: Oxford University Press; 2006.

6. Boyd C, Weiss C, Wolff J, et al. Clarifying Multimorbidity to Improve Targeting and Delivery of Clinical Services for Medicaid Populations. Trenton, NJ: Center for Health Care Strategies, Inc; 2010.

7. Slomka JM, Piette JD, Post EP, et al. Mood disorder symptoms and elevated cardiovascular disease risk in patients with bipolar disorder. J Affect Disord. 2012;138(3):405-408.

8. Lin EH, Heckbert SR, Rutter CM, et al. Depression and increased mortality in diabetes: unexpected causes of death. Ann Fam Med. 2009;7(5):414-421. 
9. Hamer M, Batty GD, Stamatakis E, Kivimaki M. The combined influence of hypertension and common mental disorder on all-cause and cardiovascular disease mortality. J Hypertens. 2010;28(12):2401-2406.

10. Stiefel FC, de Jonge P, Huyse FJ, et al. "INTERMED": a method to assess health service needs. II. Results on its validity and clinical use. Gen Hosp Psychiatry. 1999;21(1):49-56.

11. Safford MM, Allison JJ, Kiefe CI. Patient complexity: more than comorbidity. The vector model of complexity. J Gen Intern Med. 2007;22(Suppl 3):382-390.

12. Grembowski D, Schaefer J, Johnson KE, et al; AHRQ MCC Research Network. A conceptual model of the role of complexity in the care of patients with multiple chronic conditions. Med Care. 2014 52(Suppl 3):S7-S14.
13. Zulman DM, Asch SM, Martins SB, Kerr EA, Hoffman BB, Goldstein MK. Quality of care for patients with multiple chronic conditions: the role of comorbidity interrelatedness. J Gen Intern Med. 2014; 29(3):529-537.

14. Shippee ND, Shah ND, May CR, Mair FS, Montori VM. Cumulative complexity: a functional, patient-centered model of patient complexity can improve research and practice. J Clin Epidemiol. 2012 65(10):1041-1051

15. Loeb DF, Bayliss EA, Binswanger IA, Candrian C, deGruy FV. Primary care physician perceptions on caring for complex patients with medical and mental illness. J Gen Intern Med. 2012;27(8):945-952.

16. Thomas DR. A general inductive approach for analyzing qualitative evaluation data. Am J Eval. 2006;27(2):237-246.

\section{Get the Annals of Family Medicine by E-mail}

Make sure you see every new issue

while it's fresh; have the table of

contents sent to you by e-mail for

easy access to articles of interest.

Don't miss important research.

Request the e-mail table of contents at

http://www2.highroadsolution.com/

aafp_annals_preference_center/search.aspx

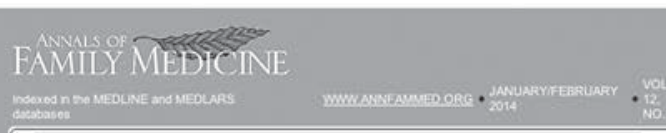

Impact Factor Announcement

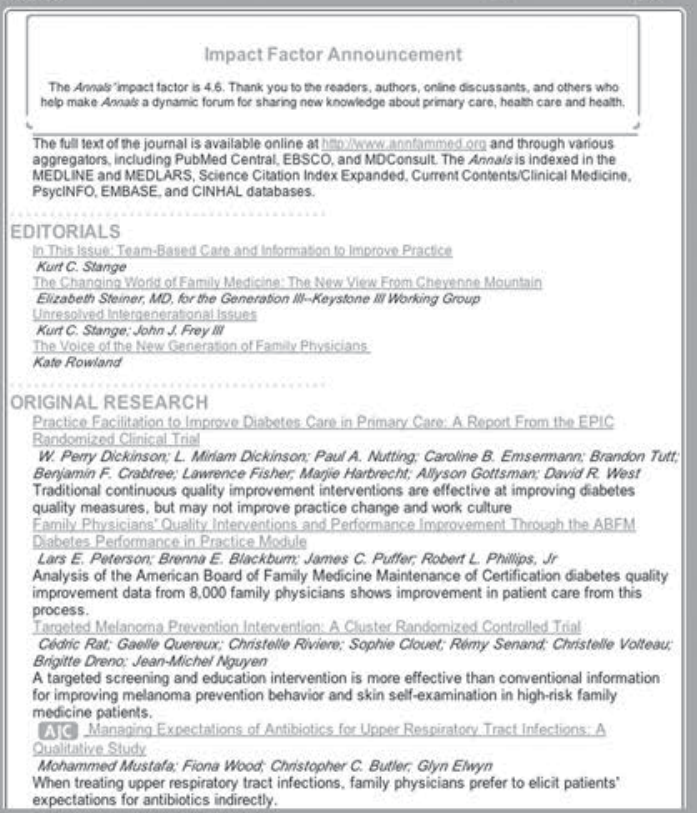

